\title{
ReMed: Unterstützung für überforderte Ärztinnen und Ärzte
}

\author{
Ihr Beruf nimmt Ärztinnen und Ärzte in Anspruch - manchmal so stark, dass sie nicht \\ mehr wissen, wie sie diese kritischen Situationen meistern sollen. Hier bietet das \\ Unterstützungsnetzwerk ReMed Halt und zeigt Auswegmöglichkeiten auf.
}

\author{
Jürg Bänninger ${ }^{a}$, \\ Maximiliano Wepfer ${ }^{b}$ \\ a Facharzt für Allgemeine \\ Medizin FMH, \\ Leitungsausschuss ReMed \\ b Kommunikation FMH
}

\begin{abstract}
Erfahrungsbericht Leben kam, erzählt:
\end{abstract}

Die Lebenspartnerin eines 48-jährigen Arztes, der unter Medikamenteneinfluss durch tragische Umstände ums

Die Zweifel lassen mich nicht los, machen mich wahnsinnig: Wäre ich früher heimgekommen, hätte ich seinen Tod vielleicht verhindern können. Ihn schützen zu wollen, war genau das Falsche, im Gegenteil, ich hätte alles riskieren müssen, um ihm zu helfen. Hätte ich schon damals von ReMed gewusst, hätte ich vielleicht anders gehandelt.

Vor etwa vier Jahren fing alles an. Mein Partner kam immer häufiger nach der Arbeit im Spital nicht mehr nach Hause. Ich wurde erst misstrauisch, als ich eines Tages im Badezimmer blutverschmierte Kleider fand. Er führte dies auf einen Sturz mit dem Fahrrad zurück - dies konnte aber nicht stimmen, entsprechende Verletzungen fehlten. Dann überraschte ich ihn auf dem Sofa mit einer Spritze im Arm, völlig benommen. Gegen seinen Willen rief ich die Ambulanz, er konnte aber die Sanitäter davon überzeugen, dass er alles Befinden Sie sich in einer schwierigen Situation und suchen Rat? Oder benötigt ein Arzt, eine Ärztin in Ihrem Umfeld Unterstützung? Dann melden Sie sich bei ReMed über die 24-StundenHotline 0800073633 oder über die Mailadresse help[at]swiss-remed.ch an. Wahrscheinlich war ich trotzdem zu wenig aufsässig, hätte einfach nachhaken müssen - oder ihn an eine Fachstelle wie ReMed verweisen können, wenn ich es früher gekannt hätte.

Als ich dann selber schwer erkrankte, unterstützte er mich liebevoll und motivierte mich für die bevorstehende Therapie. Seine eigene Suchtabhängigkeit schien wie weggeblasen, und wir hatten es so gut wie noch nie. Nachdem ich mich ein wenig erholt hatte, fiel er seinerseits in ein Loch und zog sich zurück. Wir entschlossen uns dennoch für eine gemeinsame Psychotherapie, um den Umgang mit meiner Krankheit zu lernen. Den entsprechenden Termin nahm ich alleine wahr. Ich erzählte dem Therapeuten die ganze Geschichte meiner Erfahrungen mit den Suchtproblemen meines Partners. Gestärkt und mit viel Mut kam ich aus dieser Sitzung nach Hause. Mir war nun klar, dass es so nicht weitergehen konnte und etwas geschehen musste. Leider viel zu spät. An diesem Tag ist er gestorben ...

\section{Interview mit Peter Birchler, Mitglied des Leitungsausschusses von ReMed}

Peter Birchler, zu welchem Zeitpunkt hätte sich die Lebenspartnerin des Arztes im Erfahrungsbericht an ReMed wenden können?

Je rascher, desto besser. Bei beginnendem Misstrauen sollen sich Angehörige melden. Zwar kein leichtes Unterfangen, sie wollen ja den Partner nicht kränken, aber erfahrungsgemäss können wir so vielen Betroffenen helfen.

\section{Auf welche Weise hätte ReMed sie unterstützt?}

Zunächst klären wir mit dem Ratsuchenden die Situation. Anschliessend versuchen wir, die Betroffenen zu kontaktieren, Unterstützungsangebote wie stationäre Therapien aufzuzeigen und den Motivationsprozess zu begleiten.

Obwohl verbindliche Abmachungen getroffen wurden, schaffte er es, sich ihnen zu entziehen - er überzeugte die Fachleute davon, dass kein Problem vorliege. Ich schwieg aus Angst, etwas zu tun, das ihm schaden könnte. Diese fatale Angst hinderte mich daran, mehr zu hinterfragen und einzugreifen. Und selbst als ich mich ab und zu überwinden konnte, brachte ich ihn nicht dazu, etwas dagegen zu unternehmen: Ich kam gegen sein Fachwissen nicht
Auf welche Signale giltes zuachten, um bei Suchtproblemen professionelle Hilfe in Anspruch zu nehmen?

Veränderungen im Sozial- und Arbeitsverhalten wie Rückzug, Stimmungsschwankungen oder wechselnde Leistungsfähigkeit sowie ein vernachlässigtes Erscheinungsbild sind ernstzunehmende Anzeichen.
Dr. med. Jürg Bänninger

j.baenninger[at]hin.ch 